\title{
Perceptual Factors (Awareness, Attitude) and Positive, Indeterminate and Negative Nurturing Factors Affecting Physical Activity of Pregnant Women Visiting Health-care Centers in Tehran: Examination and Analyses
}

Leila Kianfard ( $\sim$ leila_kianfard@modares.ac.ir )

Tarbiat Modares University

Farkhonde Amin SHokravi

Tarbiat Modares University

Sakineh Rakhshanderou

Shahid Beheshti University

Shamsaddin Niknami

Tarbiat Modares University

Research Article

Keywords: Pregnant women, awareness, attitude, physical activity

Posted Date: February 15th, 2021

DOI: https://doi.org/10.21203/rs.3.rs-144607/v2

License: (c) (1) This work is licensed under a Creative Commons Attribution 4.0 International License. Read Full License 


\section{Abstract}

Background: The purpose of this study was to examine the effect of perceptual factors (awareness, attitude) and positive, intermediate and negative nurturing factors on the physical activity of pregnant women visiting health centers in Tehran.

Methods: The present research was an applied study in which a quasi-experimental research design (pretest-post-test) with a control group was employed. The Pregnancy Physical Activity Questionnaire (PPAQ) and a questionnaire designed based on the results of needs assessment and dimensions of the PEN-3 model were used for this study. This study is a randomized control trial (RCT).

Results: The results indicated that the intervention based on E-learning has a statistically significant effect on perceptual factors (awareness, attitude) in increasing physical activity of pregnant women in the experimental group. Furthermore, the e-learning-based intervention has a significant effect on increasing physical activity of pregnant women in the experimental group compared to the control group.

Conclusion: Based on the research results, it can be said that there is a statistically significant difference between the experimental and control groups in the scores obtained from perceptual factors (awareness, attitude) in the pre-test and the experimental group. Furthermore, it can be said that there is a statistically significant difference between the experimental and control groups in the scores obtained from perceptual factors (awareness, attitude) in the pre-test and the experimental group.

\section{Introduction}

Pregnancy is one of the most sensitive and significant stages of any woman's life. It is associated with changes in psychological needs (e.g., anxiety and depression) and physical demands (such as weight gain and higher cardiac output). Nevertheless, about $60 \%$ of all pregnant women eliminate or reduce their physical activity during pregnancy $(1,2)$. Research shows that reduced physical activity in pregnant women is highly stemmed from their misconceptions and attitudes during pregnancy. It has been proven that regular physical activity in the first six months of pregnancy reduces the prevalence of cesarean section, shortens the second stage of labor and reduces fetal complications. In Iran, the prevalence of required training following standard pregnancy care programs is not satisfactory. Women experience unavoidable weight gain during pregnancy, while the role of physical activity during pregnancy to prevent such problems is significant (3).

Furthermore, guides specifically designed with the characteristics of pregnancy in mind are less available. The World Health Organization defines physical activity as "any physical movement produced by skeletal muscle that requires energy consumption, including activities such as working, playing, doing household chores, traveling, and taking responsibility for recreational activities" (4). Although many studies show the beneficial effects of physical activity on the overall health of mother and fetus and having a healthy pregnancy, about $60 \%$ of all pregnant women do not undertake any physical activity during pregnancy (1). Despite the prevalence of awareness on exercise's physiological manifestations during pregnancy, 
there is still no comprehensive understanding of exercise's effects with different intensities and intervals during pregnancy on mother and fetus (5). The postpartum period can be introduced as an opportunity to change health-related habits throughout life. Unfortunately, limited interventions have been proposed based on health education theories and models in this regard (6-7), and most studies have been descriptive and analytical. Considering the vital role of mothers, their health is significantly involved in the health of infants. Maternal factors during pregnancy such ways employed for reducing the concentration of blood in diabetic mothers, reducing back pain, increasing mental activity, improving quality of life and increasing physical function, type of nutrition, strategies used to cope with stress and overall care during this period constitute an important part of the mother's lifestyle during pregnancy (8). Significant developments have been achieved in technology and studies related to exercise for pregnant women. However, the most optimal methods for encouraging pregnant women to engage in physical activity are yet to be examined. There are no studies on implementing an effective e-learning program, one that considers society's cultural dimension to increase physical activity in pregnant women in Iran. It is also necessary to develop programs for the prevalence of exercises in pregnant women. Given the importance

of physical activities during pregnancy and the necessity to implement suitable interventions in line with the improvement of the attitude mentioned above among pregnant women, it is also of paramount importance to use modern methods and technologies to entice women to increase their activity levels during pregnancy, the purpose of which would be to reduce the incidence of pregnancy-related diseases and hence to reduce the rate of cesarean section in Iran and the world. This study sought to answer the following question: what are the perceptual factors (awareness, attitude) that increase physical activity in pregnant women referring to health-care centers?

\section{Materials And Methods}

This research is an applied study for purpose, employing a mixed-method (quantitative and qualitative) design for data collection. The research was conducted in two stages. In the first stage of the research, the literature was first reviewed, followed by semi-organized interviews with pregnant women, to obtain the criteria and sub-criteria for increasing physical activity in pregnant women. Demographic characteristics are shown in Table 1. The method employed at this stage of research was that of qualitative. In the second stage of the research, based on the previous stage's information, the researcher finally implemented an e-learning program intervention to increase physical activity in pregnant women visiting health centers in Tehran based on the PEN-3 cultural model. Thus, the second stage of the research was a quasi-experimental study, which was performed quantitatively. This study was, in fact, a randomized control trial (RCT). A quasi-experimental research design (pre-test/post-test) with a control group was employed for the study, given the research's nature.

Table 1: Results of factor analysis of questionnaire structures 


\begin{tabular}{|c|c|c|c|}
\hline & Item & $\begin{array}{c}\text { Factor } \\
\text { load }\end{array}$ & $\begin{array}{c}\text { T- } \\
\text { value }\end{array}$ \\
\hline \multirow{20}{*}{$\begin{array}{l}\text { Awareness- } \\
\text { related } \\
\text { perceptual } \\
\text { factors }\end{array}$} & $\begin{array}{c}\text { During pregnancy, it is better to do less intense physical } \\
\text { activity than before pregnancy. }\end{array}$ & 0.25 & 3.41 \\
\hline & $\begin{array}{l}\text { To prevent pregnancy-related overweight, physical activity } \\
\text { is crucial. }\end{array}$ & 0.37 & 5.41 \\
\hline & $\begin{array}{l}\text { Exercise during pregnancy reduces the oxygen supply to } \\
\text { the baby. }\end{array}$ & 0.45 & 6.69 \\
\hline & $\begin{array}{l}\text { During pregnancy, exercises should be performed on } \\
\text { smooth surfaces without slopes. }\end{array}$ & 0.37 & 5.42 \\
\hline & $\begin{array}{c}\text { Pregnant women should avoid bending and hunching } \\
\text { during exercise. }\end{array}$ & 0.26 & 3.74 \\
\hline & $\begin{array}{l}\text { Those who do not exercise give birth to diabetic babies } \\
\text { more often. }\end{array}$ & 0.38 & 5.56 \\
\hline & Exercise during pregnancy facilitates natural childbirth. & 0.34 & $4.9^{`}$ \\
\hline & $\begin{array}{l}\text { Doing proper daily exercise will not harm the mother and } \\
\text { fetus. }\end{array}$ & 0.09 & $23 / 1$ \\
\hline & $\begin{array}{l}\text { Physical exercise alleviates pregnancy-related } \\
\text { complications such as low back pain and pelvic pain, } \\
\text { constipation and extreme fatigue. }\end{array}$ & 0.36 & 5.19 \\
\hline & Heavy exercises should be avoided during pregnancy. & 0.29 & 4.13 \\
\hline & $\begin{array}{l}\text { Performing light exercises to warm up is essential before } \\
\text { starting exercise during pregnancy. }\end{array}$ & 0.45 & 6.58 \\
\hline & $\begin{array}{l}\text { Stretching and strength exercises during pregnancy } \\
\text { should be performed only in consultation with an expert. }\end{array}$ & 0.34 & 4.89 \\
\hline & $\begin{array}{l}\text { Exercising during pregnancy avoids the risks of high } \\
\text { blood pressure. }\end{array}$ & 0.19 & 2.63 \\
\hline & $\begin{array}{l}\text { Exercise during pregnancy leads to a faster return to the } \\
\text { mother's initial weight after delivery. }\end{array}$ & 0.35 & 5.03 \\
\hline & $\begin{array}{c}\text { Pregnant women should try to avoid lifting any weights } \\
\text { during pregnancy. }\end{array}$ & 0.59 & 8.99 \\
\hline & $\begin{array}{l}\text { Exercising during pregnancy leads to fitness and weight } \\
\text { control. }\end{array}$ & 0.17 & 2.42 \\
\hline & $\begin{array}{c}\text { To prepare before exercise, performing } 15 \text { minutes of } \\
\text { light exercises is necessary. }\end{array}$ & 0.49 & 7.37 \\
\hline & $\begin{array}{l}\text { It is necessary to consult with a professional before doing } \\
\text { any exercise during this period. }\end{array}$ & 0.21 & 2.93 \\
\hline & Exercise reduces the risk of musculoskeletal disorders. & 0.30 & 4.28 \\
\hline & $\begin{array}{l}\text { In the third trimester of pregnancy, the intensity of } \\
\text { exercise should decrease. }\end{array}$ & 0.39 & 5.69 \\
\hline $\begin{array}{l}\text { Attitude-related } \\
\text { perceptual }\end{array}$ & $\begin{array}{l}\text { I believe that by exercising I can easily cope with } \\
\text { complications like gestational diabetes. }\end{array}$ & 0.56 & 8.90 \\
\hline
\end{tabular}




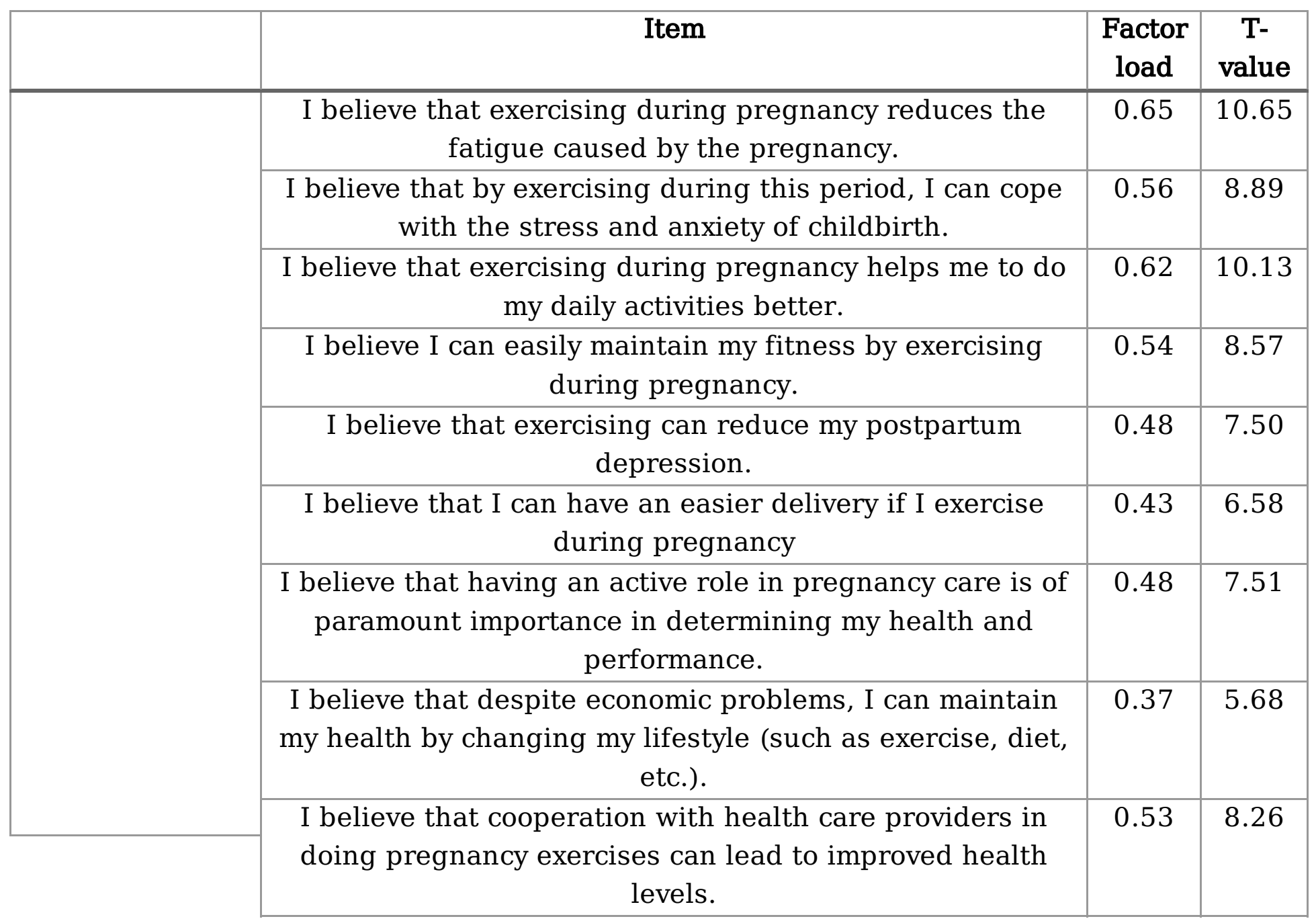

The study population included all pregnant women aged 18 to 40 years with the gestational age of 1238 weeks visiting health-care centers in Tehran's District 5 out of all 22 districts of the city that had eliminated their physical activity pregnancy.

In the qualitative stage, the sample size was determined based on the necessity of data saturation, and as such, interviewing continued until it was achieved. Sampling was performed using simple random sampling among those invited to participate in the health center study. Thus, after sending invitations to pregnant women who were in their first pregnancy and conducting telephone follow-ups by an expert and the head of the health center, 23 people were selected from the mothers who visited the health center.

\section{Data Collection tools}

A. Semi-structured interviews with semi-structured questions for small group discussion among pregnant women and their families, along with individual interviews with health care providers and health professionals

B. Questionnaires 
1. Questionnaire for examining demographic variables including personal characteristics and disease information

2. Questionnaire designed based on the results of needs assessment and dimensions of PEN-3 model

This questionnaire was a researcher-made questionnaire, with three categories and 42 items. The categories include perceptual factors with 20 items, nurturing factors with 10 items, and enabling factors with 12 items. The items are scored on a 5-point Likert scale ranging from strongly agree to disagree strongly. The questionnaire's validity was confirmed using content validity, while its internal reliability was confirmed following a confirmatory study among 250 pregnant mothers with similar traits to that of the study group. The reliability of the questionnaire was confirmed with Cronbach's alpha coefficient (0.85). The results of the validity and reliability of the tools were presented.

\section{Pregnancy Physical Activity Questionnaire (PPAQ)}

This questionnaire consists of two parts; the first part pertains to personal characteristics, and the second part consists of 32 items on physical activity, which itself is divided into four groups of items, namely household/caregiving activities (16 items), transportation (3 items), occupational activities (5 items) and entertainment and sports (8 items). Activity intensity was calculated based on the Metabolic equivalent of task (MET), a unit for estimating metabolic expenditure in physical activity per unit of time. Its reliability was determined by conducting a preliminary study on 3 eligible pregnant women, attaining a Cronbach's alpha of 0.85 .

\section{Validity And Reliability Of The Questionnaire}

Face validity: The questionnaires were first administered among at least 15 pregnant women visiting health centers, then the face validity was determined based on the importance of the items and by calculating the impact score. Items with an impact score higher than 1.5 were deemed appropriate for subsequent analysis.

Content validity: The experts' panel's opinions were extracted and used accordingly to determine the content validity. To quantitatively evaluate the content validity, two coefficients of content validity ratio and content validity index were used.

Content Validity Ratio (CVR): At least 15 specialists and experts responded to each item through 3 choices for each (i.e., the item is necessary, the item is useful but not necessary, the item is not necessary). Items whose resulting scores were larger than the Lawshe table's relevant value were considered necessary items.

Content Validity Index (CVI): To ensure that items were optimally designed to measure structures, three criteria of relevance, clarity, and simplicity were examined using an 8-point Likert scale, as at least 15 specialists examined each item. CVI scores higher than 0.79 was deemed appropriate. 
Reliability test: To determine the reliability of the data collection tool, a modified questionnaire was distributed among 30 people in the study population, and Cronbach's alpha value was calculated. An alpha value higher than 0.7 was considered proper for this study.

\section{Data Analysis Method}

In the first stage, qualitative data were coded immediately after each group discussion and individual interview, and these sessions were continued until data saturation. The main themes and topics were extracted using MAX-QDA software and based on deductive qualitative content analysis. Descriptive statistical methods such as mean and inferential statistics were employed to analyze the data.

\section{Integration Through Inclusive Themes}

In the thematic analysis, the themes formed in the interviews were integrated under broad themes, and a network of themes, namely "Factors Affecting Physical Activity Based on the PEN-3 Cultural Model," was formed, which is shown in Fig. 1.

\section{Quantitative Data Analysis}

In this section, structural measurement models were employed to examine the accuracy of measuring structures by the corresponding indicators.

Table 2 shows that the confirmatory factor analysis of the constructs of the questionnaires on the impact of e-learning program to increase physical activity of pregnant women visiting health-care centers in Tehran based on the PEN-3 cultural model has a suitable fit, and thus the constructs of the questionnaire measure the relevant variables properly. 
Table 2

Results of factor analysis of questionnaire structures

\begin{tabular}{|c|c|c|c|}
\hline & Item & $\begin{array}{l}\text { Factor } \\
\text { load }\end{array}$ & $\begin{array}{l}\mathrm{T}- \\
\text { value }\end{array}$ \\
\hline \multirow{18}{*}{$\begin{array}{l}\text { Awareness- } \\
\text { related } \\
\text { perceptual } \\
\text { factors }\end{array}$} & $\begin{array}{l}\text { During pregnancy, it is better to do less intense physical } \\
\text { activity than before pregnancy. }\end{array}$ & 0.25 & 3.41 \\
\hline & $\begin{array}{l}\text { To prevent pregnancy-related overweight, physical activity is } \\
\text { crucial. }\end{array}$ & 0.37 & 5.41 \\
\hline & $\begin{array}{l}\text { Exercise during pregnancy reduces the oxygen supply to the } \\
\text { baby. }\end{array}$ & 0.45 & 6.69 \\
\hline & $\begin{array}{l}\text { During pregnancy, exercises should be performed on smooth } \\
\text { surfaces without slopes. }\end{array}$ & 0.37 & 5.42 \\
\hline & $\begin{array}{l}\text { Pregnant women should avoid bending and hunching during } \\
\text { exercise. }\end{array}$ & 0.26 & 3.74 \\
\hline & $\begin{array}{l}\text { Those who do not exercise give birth to diabetic babies more } \\
\text { often. }\end{array}$ & 0.38 & 5.56 \\
\hline & Exercise during pregnancy facilitates natural childbirth. & 0.34 & $4.9^{`}$ \\
\hline & Doing proper daily exercise will not harm the mother and fetus. & 0.09 & $23 / 1$ \\
\hline & $\begin{array}{l}\text { Physical exercise alleviates pregnancy-related complications } \\
\text { such as low back pain and pelvic pain, constipation and } \\
\text { extreme fatigue. }\end{array}$ & 0.36 & 5.19 \\
\hline & Heavy exercises should be avoided during pregnancy. & 0.29 & 4.13 \\
\hline & $\begin{array}{l}\text { Performing light exercises to warm up is essential before } \\
\text { starting exercise during pregnancy. }\end{array}$ & 0.45 & 6.58 \\
\hline & $\begin{array}{l}\text { Stretching and strength exercises during pregnancy should be } \\
\text { performed only in consultation with an expert. }\end{array}$ & 0.34 & 4.89 \\
\hline & $\begin{array}{l}\text { Exercising during pregnancy avoids the risks of high blood } \\
\text { pressure. }\end{array}$ & 0.19 & 2.63 \\
\hline & $\begin{array}{l}\text { Exercise during pregnancy leads to a faster return to the } \\
\text { mother's initial weight after delivery. }\end{array}$ & 0.35 & 5.03 \\
\hline & $\begin{array}{l}\text { Pregnant women should try to avoid lifting any weights during } \\
\text { pregnancy. }\end{array}$ & 0.59 & 8.99 \\
\hline & $\begin{array}{l}\text { Exercising during pregnancy leads to fitness and weight } \\
\text { control. }\end{array}$ & 0.17 & 2.42 \\
\hline & $\begin{array}{l}\text { To prepare before exercise, performing } 15 \text { minutes of light } \\
\text { exercises is necessary. }\end{array}$ & 0.49 & 7.37 \\
\hline & $\begin{array}{l}\text { It is necessary to consult with a professional before doing any } \\
\text { exercise during this period. }\end{array}$ & 0.21 & 2.93 \\
\hline
\end{tabular}




\begin{tabular}{|c|c|c|c|}
\hline & Item & $\begin{array}{l}\text { Factor } \\
\text { load }\end{array}$ & $\begin{array}{l}\mathrm{T}- \\
\text { value }\end{array}$ \\
\hline & Exercise reduces the risk of musculoskeletal disorders. & 0.30 & 4.28 \\
\hline & $\begin{array}{l}\text { In the third trimester of pregnancy, the intensity of exercise } \\
\text { should decrease. }\end{array}$ & 0.39 & 5.69 \\
\hline \multirow{10}{*}{$\begin{array}{l}\text { Attitude-related } \\
\text { perceptual } \\
\text { factors }\end{array}$} & $\begin{array}{l}\text { I believe that by exercising I can easily cope with } \\
\text { complications like gestational diabetes. }\end{array}$ & 0.56 & 8.90 \\
\hline & $\begin{array}{l}\text { I believe that exercising during pregnancy reduces the fatigue } \\
\text { caused by the pregnancy. }\end{array}$ & 0.65 & 10.65 \\
\hline & $\begin{array}{l}\text { I believe that by exercising during this period, I can cope with } \\
\text { the stress and anxiety of childbirth. }\end{array}$ & 0.56 & 8.89 \\
\hline & $\begin{array}{l}\text { I believe that exercising during pregnancy helps me to do my } \\
\text { daily activities better. }\end{array}$ & 0.62 & 10.13 \\
\hline & $\begin{array}{l}\text { I believe I can easily maintain my fitness by exercising during } \\
\text { pregnancy. }\end{array}$ & 0.54 & 8.57 \\
\hline & $\begin{array}{l}\text { I believe that exercising can reduce my postpartum } \\
\text { depression. }\end{array}$ & 0.48 & 7.50 \\
\hline & $\begin{array}{l}\text { I believe that I can have an easier delivery if I exercise during } \\
\text { pregnancy }\end{array}$ & 0.43 & 6.58 \\
\hline & $\begin{array}{l}\text { I believe that having an active role in pregnancy care is of } \\
\text { paramount importance in determining my health and } \\
\text { performance. }\end{array}$ & 0.48 & 7.51 \\
\hline & $\begin{array}{l}\text { I believe that despite economic problems, I can maintain my } \\
\text { health by changing my lifestyle (such as exercise, diet, etc.). }\end{array}$ & 0.37 & 5.68 \\
\hline & $\begin{array}{l}\text { I believe that cooperation with health care providers in doing } \\
\text { pregnancy exercises can lead to improved health levels. }\end{array}$ & 0.53 & 8.26 \\
\hline
\end{tabular}

Given that all significant variables of model parameters except the item "doing daily basic exercise will not harm the mother and fetus" is greater than 1.96 , the validity of the measurement structures for the relevant variables at a significant level is confirmed.

In the research model, the root means the square error of approximation (RMSEA) is 0.038 , less than 0.1 . Moreover, other fitness indicators are also listed in the table below. As can be seen, they confirm the significance and fit of the model.

\section{Descriptive Statistics Of Variables}

The results of descriptive statistics on the pre-and post-test of the variables of "awareness" and "attitude" in the experimental and control groups are given in Table 3. 
Table 3

Pre- and post-test results of variables in experimental and control groups

\begin{tabular}{|lllll|}
\hline Variable (pre-test) & \multicolumn{3}{c}{ Experimental group } & \multicolumn{2}{l}{ Control group } \\
\cline { 2 - 6 } & Mean & SD & Mean & SD \\
\hline Awareness & 24.30 & 12.51 & 22.45 & 13.11 \\
\hline Attitude & 22.31 & 6.70 & 24.32 & 6.42 \\
\hline Perceptual factors & 46.61 & 12.74 & 46.77 & 14.13 \\
\hline Increased physical activity & 82.26 & 12.75 & 82.43 & 14.51 \\
\hline Post-test & & & & \\
\hline Awareness & 30.42 & 10.44 & 25.82 & 11.00 \\
\hline Attitude & 43.56 & 5.31 & 34.79 & 4.57 \\
\hline Increased physical activity & 127.11 & 13.17 & 100.00 & 12.88 \\
\hline
\end{tabular}

\section{Inferential Statistics}

\section{Default values for analysis of covariance}

According to the values of Table 4 and considering that the level of significance for all the variables of "awareness", "attitude", "perceptual factors," and "increase in physical activity" is higher than 0.05, it can be concluded that the relevant variable has a normal distribution. 
Table 4

Default values of covariance analysis for research variables

\begin{tabular}{|lcccc|}
\hline Variables & \multicolumn{2}{c|}{ Kolmogorov-Smirnov } & Significance level \\
\hline Awareness & \multicolumn{2}{c}{0.208} & & 0.000 \\
\hline Attitude & 0.089 & & 0.000 \\
\hline Increased physical activity & & 0.117 & & 0.000 \\
\hline Homogeneity of variances & Levene value & df1 & df2 & Significance level \\
\hline Awareness & 0.001 & 1 & 198 & 0.971 \\
\hline Attitude & 0.037 & 1 & 198 & 0.847 \\
\hline Increased physical activity & 0.135 & 1 & 198 & 0.714 \\
\hline Homogeneity of regression slope & Df & F & Significance level \\
\hline Awareness & 1 & 1.723 & $\mathbf{1 . 1 9 1}$ \\
\hline Attitude & 1 & 3.595 & 0.059 \\
\hline Increased physical activity & 1 & 0.004 & 0.951 \\
\hline
\end{tabular}

Furthermore, according to the same table and considering that the significance level of Levene test for all the variables of "awareness", "attitude", "perceptual factors," and "increase in physical activity" is higher than 0.05 , it can be argued that the experimental and control groups have homogeneous variances.

Considering that none of the variables of "awareness", "attitude", "perceptual factors," and "increase in physical activity" are significant in examining the homogeneity of regression slope $(P>.05)$, we conclude that the assumption of homogeneity of regression slope holds.

\section{Examining the hypotheses}

1. Intervention based on e-learning has a significant effect on perceptual factors (awareness, attitude) to increase physical activity in pregnant women in the experimental group.

To test Hypothesis 1, multivariate analysis of covariance was performed while controlling the possible effect of pre-tests, the results of which can be seen in Table 5. Covariance analysis is a comprehensive type of analysis of variance. The effect of one or more control or interfering variables and covariates is excluded from the equation while comparing the means of one or more groups and estimating one or more independent variables. This analysis is a statistical method that allows the effect of one independent variable on the dependent variable to be examined while eliminating the effect of another variable. 
Table 5

Multivariate statistical indices in analysis of variance of dependent variables

\begin{tabular}{|lllllll|}
\hline Trace & Value & $\mathbf{F}$ & Hypothesis df & Error df & Sig. & Size \\
\hline Pillai's Trace & 0.202 & 24.859 & 2 & 197 & 0.000 & 0.202 \\
\hline Wilks Lambda & 0.789 & 24.859 & 2 & 197 & 0.025 & 0.202 \\
\hline Hotelling's Trace & 0.752 & 24.859 & 2 & 197 & 0.025 & 0.202 \\
\hline Roy's Largest Root & 0.252 & 24.859 & 2 & 197 & 0.025 & 0.202 \\
\hline
\end{tabular}

The results from Wilkes lambda test indicated that the effect of interventions based on e-learning on the combination of variables of perceptual factors (i.e., awareness and attitude) was significant $(F=24.859$, $p<0.05$ ). The above test allowed the use of multivariate analysis of variance (MANOVA). The size of the different effect is proper considering the eta-value (0.202). The results of multivariate analysis of covariance in Table 6 showed that the mean scores of perceptual factors, i.e., awareness (2080.125) and attitude (2284.880), were significantly higher in pregnant women in the experimental group than those in the control group, and as such it can be concluded that Intervention based on e-learning has a significant effect on perceptual factors (awareness, attitude) that aim to increase physical activity of pregnant women in the experimental group.

Table 6

Results of multivariate analysis of covariance on dependent variables

\begin{tabular}{|lllllll|}
\hline Dependent variables & Sum of squares & Df & average of squares & F & Sig. & Size \\
\hline Awareness & 2080.125 & 1 & 2080.125 & 4.592 & 0.033 & 0.023 \\
\hline Attitude & 2284.880 & 1 & 2284.880 & 45.029 & 0.000 & 0.185 \\
\hline
\end{tabular}

\section{Intervention based on elearning has a significant effect on increasing physical activity in the experimental group's pregnant women compared to those of the control group.}

According to Table 7, pregnant women $(F=320.395, P<0.05)$ received a significant impact from the intervention based on e-learning in the physical activity variable. As a result, the null hypothesis is rejected, and thus the research hypothesis is accepted. In other words, the e-learning-based intervention has a significant effect on the level of physical activity in pregnant women.

Table 7

Results of one-way analysis of covariance for physical activity

\begin{tabular}{|lllllll|}
\hline Dependent variables & Sum of squares & Df & average of squares & F & Sig. & Size \\
\hline Physical activity & 36996.391 & 1 & 36996.391 & 320.395 & 0.000 & 0.619 \\
\hline
\end{tabular}




\section{Conclusion}

In this study, positive, indeterminate and negative perceptual factors (awareness, attitude) affecting physical activity in pregnant women referred to health centers in Tehran were examined, and the following results were obtained:

\section{Hypothesis 1}

Intervention based on e-learning has a significant effect on perceptual factors (awareness, attitude) that increase pregnant women's physical activity in the experimental group.

Based on the research results, it can be said that there is a statistically significant difference between the experimental and control groups in the scores obtained from perceptual factors (awareness, attitude) in the pre-test and the experimental group. After instructing the intervention based on e-learning in various sessions for pregnant women, the tested perceptual factors (awareness, attitude) were affected perceptual factors (awareness, attitude) of pregnant women were improved, thus confirming the research hypothesis. The results of the research are consistent with those of Garshasbi et al. (2014). Garshasbi et al. (2014) performed a study to examine sports beliefs and behaviors and physical activity of women during pregnancy and postpartum based on the theory of planned behavior, in which the amount of physical activity and sports beliefs of 200 women in the period 1 year after birth was assessed using the Global Physical Activity Questionnaire and the Sports Beliefs Questionnaire. The results indicated that the most common behavioral beliefs in pregnancy and postpartum are that exercise improves mood and spirit, reduces stress, controls weight and results in fitness. Wife, mother and health care workers were the most influential people (9). To elaborate, it is safe to argue that the first step in physical activity training is to improve awareness and attitude on the importance and manner of physical activity, as improving awareness and attitude naturally leads to behavioral changes. Today, the amount of training required according to standard pregnancy care programs is not optimal. It seems that mothers are highly concerned about sports during pregnancy owing to their lack of knowledge about permitted sports and the relevant procedures. Since incorrect information is one of the factors affecting their behavior, it causes women to opt for a rather sedentary life during pregnancy (10). Increasing awareness and readiness during pregnancy allows the mother to go through this life stage with fewer complications. As such, pregnancy poses a good opportunity to educate pregnant women to be aware of the benefits of good physical activity and a healthy lifestyle. Increasing women's awareness of physical activity and physical exercises during pregnancy and changing their attitude will naturally lead to behavioral changes.

\section{Hypothesis 2}

Intervention based on e-learning has a significant effect on increasing physical activity in the experimental group's pregnant women compared to those of the control group. 
Based on the study's findings, it is safe to say that there is a statistically significant difference between the experimental and control groups in the scores obtained from physical activity in the pre-test and the experimental group. After instructing the intervention based on e-learning in various sessions for pregnant women, the increase in physical activity was evident, and the physical activity of pregnant women was increased, hence confirming the research hypothesis. The results of this study are in line with those of Kazemi et al. (2007), Abbasi et al. (2015), and Taheri et al. (2016). The increase in the mean score of physical activity in the experimental group's women indicates that the experimental group has actively sought to follow the standard activity recommendations presented in the training class. In this study, the activity of mothers in the experimental group has improved. Kazemi et al. (2007) concluded that the rate of physical activity in women without gestational hypertension was significantly higher than in the group with hypertension (11). Shakeri et al. (2012) performed a study to determine the effect of physical activity training during pregnancy on pregnant women's physical activity. In this interventional and quasiexperimental study, two groups of 140 pregnant women in their first pregnancy referred to health-care centers in Zanjan were selected and randomly divided into experimental and control groups. Based on the results, the amount of physical activity in women in the experimental and control groups before the intervention was not significantly different.

Nevertheless, after the intervention, the experimental group's physical activity was significantly higher than the control group (12). Another study results revealed that pregnancy training classes' administration promotes behaviors related to a healthy lifestyle and leads to increased physical activity. Using the experiences and verbal advice of midwives and studying written training materials can improve physical activity during pregnancy. Therefore, it is necessary to recommend physical activity during pregnancy (13).

\section{Declarations}

\section{Ethics approval and consent to participate}

The Research Ethics Committee approved the research of this study. In this in-depth interview, all pregnant women were informed about participating in the survey and gave written informed consent for the study. All methods were performed following the relevant guidelines and regulations.

\section{Consent for publication}

Not applicable

\section{Availability of data and materials}

All data generated during the process of this research are included in this article.

\section{Competing interests}


The authors declare that they have no competing.

\section{Funding}

This study is funded in part by the Medical Sciences, Tarbiat Modares University, Department of Health Education and Health Promotion. This funding has facilitated the use of websites to support physical activity during pregnancy.

\section{Authors' contributions}

LK comprehended the trial, completed the collection, categorized and coding the data. SR presented supervision during data collection and collaborated to temporary and interpret final data and edition transcription. SHN performed management during the development of the study and data gathering. FSH participated in the analysis of the data, prepared the draft, and edited the repetitive draft. All researchers read, concluded, and approved the final draft.

\section{Acknowledgments}

We gratefully thank all the pregnant women, their families, and health centers who accompanied us along with this study. We would also like to thank the research deputy of Tarbiat Modares University for its financial support. This study was a part of the first author's doctoral dissertation in health education and promotion at the Faculty of Medical Sciences, Tarbiat Modares University. It was approved by the university's institutional review board (IRB) on August 18, 2018. We wish to acknowledge the assistance and support of authorities and faculty members in the Faculty of Medicine and Tarbiat Modarres University. The authors would like to extend their thanks to the Ministry of Education and District Five authorities, and Tehran staff for implementing the project.

\section{Authors' information}

${ }^{1}$ Department of Health Education and Health Promotion, Student of Health Education and Health Promotion in the faculty of Medical Sciences, Tarbiat Modares University, Tehran, Iran. ${ }^{2}$ Department of Health Education and Health Promotion, Faculty of Medical Sciences, Tarbiat Modares University, Tehran, Iran. ${ }^{3}$ Department of Health Education and Health Promotion, Faculty of Medical Sciences, Shahid Beheshti University, Tehran, Iran. ${ }^{4}$ Department of Health Education and Health Promotion, Faculty of Medical Sciences, Tarbiat Modares University, Tehran, Iran.

\section{References}

1-Wiebe HW, Boulé NG, Chari R, Davenport MH. The effect of supervised prenatal exercise on fetal growth: a meta-analysis. Obstet Gynecol 2015;125(5):1185-1194

2-Abasi S, Moazami M, Bijeh N, Mirmajidi R. Investigating the relationship between physical activity level with body weight (before delivery) and serum cortisol levels (during labor) in primpara women. IJOGI. 
3-Moosavinejad N, Shahmohamadi SH, Aminshokravi F. Impact of cognitive skills training on reducing depression among clients during pregnancy \& postpartum referring to health Centers. Volume 3 , Issue 1 , Spring 2015

4-Bisson M, Alméras N, Dufresne SS, et al. A 12-Week Exercise Program for Pregnant Women with Obesity to Improve Physical Activity Levels: An Open Randomised Preliminary Study. PLoS ONE 2015;10(9): e0137742

5-ShiY, DeGrohM, MorrisonH.Perinatal and early childhood factors for overweight and obesity in young Canadian children. Can J Public Health 2013;104(1): e69-e74

6-Groth SW, David T. New mothers' views of weight and exercise. MCN The American journal of maternal child nursing2008;33(6):364-9

7-Aittasalo M, Pasanen M, Fogelholm M, Kinnunen TI,Ojala K, Luoto R. Physical activity counseling in maternity and child health care-a controlled trial. BMC Womens Health 2008; 8:14-18

8-Stuart A, Amer-Wåhlin I, Persson J, KällenK.Long-termcardiovascular risk in relation to birth weight and exposure to maternal diabetes mellitus. Int J Cardiol 2013;168(3):2653-2657

9-Garshasbi1 A, Moayed Mohseni S, Rafiey M, Ghazanfari Z. Evaluation of women's exercise and physical activity beliefs and behaviors during their pregnancy and postpartum based on the planned behavior theory. Scientific-Research Journal of Shahed University.2015; 22(115): 7-17

10-Nooyi, E., Nazemzadeh, M., \& Nakhei, N. (2010). The study of knowledge, attitude and practice of puerperal women about exercise during pregnancy. Iran Journal of Nursing, 23(66), 64-72.

11-Kazemi A, Ahmadi P. Relationship between physical activity in the first twenty weeks of pregnancy and the incidence of gestational hypertension. Journal of Shahrekord University of Medical Sciences2007; 9(2): $20-27$

12-Shakeri M, Fekri SH, Shahnavaz A, Shakibazadeh E. Effectiveness of a group-based educational program on physical activity among pregnant women. Journal of Nursing and Midwifery, University of Medical Sciences.2012; 18(3): 1-9

13-Eyler AA, Baker E, Cromer L, King AC, Brownson RC, Donatelle RJ. Physical Activity and Minority Women: A Qualitative Study. Health Educ Behav. 1998; 25:640-52.

\section{Figures}




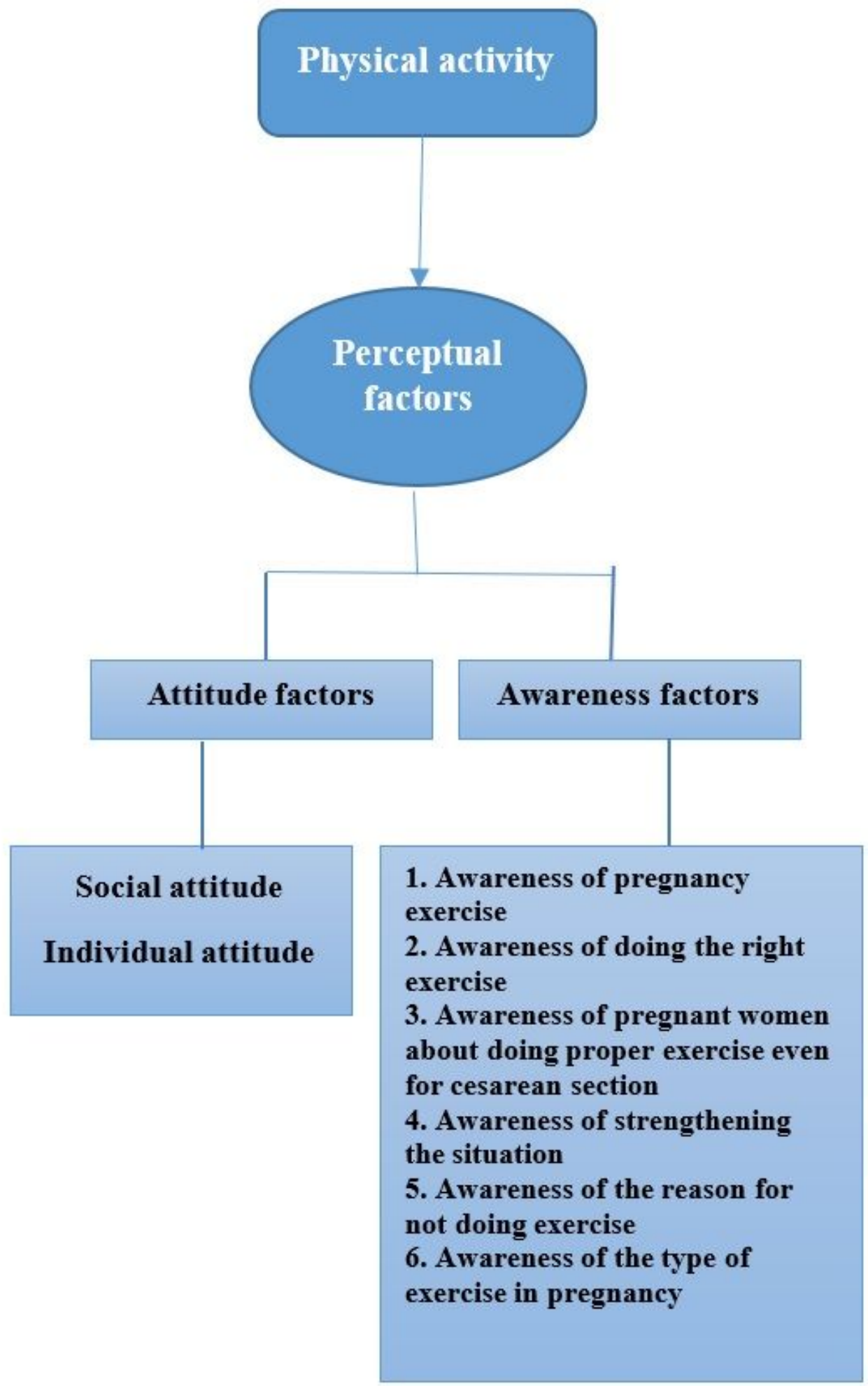

Figure 1

Conceptual model of factors affecting physical activity based on PEN-3 cultural model 